\title{
CAPTAÇÃO E SUBVERSÃO DE PRÁTICAS INTERSEMIÓTICAS: \\ uma análise discursiva no contexto político brasileiro
}

\author{
Fabio Sampaio de Almeida \\ CEFET/RJ \\ https://orcid.org/0000-0002-1710-352X \\ Alice Moraes Rego de Souza \\ CEFET/RJ \\ https://orcid.org/0000-0003-3618-7199 \\ Maria Cristina Giorgi \\ CEFET/RJ \\ http://orcid.org/0000-0001-5347-6115
}

\section{RESUMO:}

Neste artigo, buscando articular contribuições da Análise do Discurso enunciativa, às propostas de Bakhtin quanto ao dialogismo e aos gêneros de discurso, objetivamos discutir os processos de captação e subversão (MAINGUENEAU, 1997), no contexto da internet, de um gênero do discurso intersemiótico para produzir um posicionamento outro, marcado pelo embate entre diferentes formações discursivas. À luz desses referenciais teóricos, empreendemos uma análise discursiva de uma capa da revista Exame, abordando a questão da reforma da previdência no Brasil - proposta pelo governo de Michel Temer em 2016 - e de uma paródia desse mesmo texto. Os resultados de análise possibilitam compreender que captação e subversão são parte de um mesmo processo e que, no âmbito de práticas intersemióticas na internet entre diferentes formações discursivas fazem parte do repertório da competência discursiva de uma comunidade que se posiciona contra discursos neoliberais. Por meio deste percurso pautado na perspectiva discursiva, esperamos colaborar, em termos teórico-analíticos, com pesquisas que se voltam para a análise de textos verbo-visuais oriundos da internet, propondo a 
reflexão sobre saberes produzidos em enunciados que circulam atualmente em nosso país sobre temas de natureza política.

PALAVRAS-CHAVE: dialogismo e interdiscurso; gêneros do discurso; capa de revista; captação e subversão; reforma da previdência.

\title{
CAPTURE AND SUBVERSION OF INTERSEMIOTIC PRACTICES: \\ a discursive analysis in the Brazilian political context
}

\begin{abstract}
In this article, seeking to articulate contributions from the enunciative Discourse Analysis with Bakhtin's proposals regarding dialogism and discourse genres, we aim to discuss the processes of capture and subversion (MAINGUENEAU, 1997), in the context of the internet, of a genre of intersemiotic discourse to produce another position, marked by the confrontation between different discursive formations. In light of these theoretical frameworks, we undertake a discursive analysis of a cover of Exame magazine, approaching the issue of social security's reform in Brazil - proposed by Michel Temer's government in 2016 - and a parody of that same text. The results of the analysis allows to comprehend that both capture and subversion are part of the same process and that, in the context of intersemiotic practices on the Internet between different discursive formations, they are part of a discursive competence repertoire of a community that stands against neoliberal discourses. Through this course, we hope to collaborate, in theoretical-analytical terms, with researches that focuses on the analysis of verb-visual texts from the internet through a discursive perspective, proposing the reflection on knowledge produced in statements that currently circulate in our country about themes of a political nature.

KEYWORDS: dialogism; speech genres; magazine cover; capture and subversion; social security's reform.
\end{abstract}




\section{Considerações iniciais}

$\mathrm{Na}$ contemporaneidade, especialmente no ambiente midiático digital - que possibilita uma maior interação entre pessoas na produção e circulação de textos -, atores sociais participam de debates políticos por meio da apropriação e manipulação de textos de diversos gêneros, especialmente aqueles com traços intersemióticos (MAINGUENEAU, 2008), produzindo posicionamentos discursivos que se alinham ou se contrapõem a outros. Com a popularização da tecnologia, surgiram novas formas de produção e circulação de textos, marcadas pela agilidade nos processos de leitura e escrita, e pela supervalorização da imagem, por meio de gêneros como memes, infográficos, fotomontagens.

Essas novas formas de produção e consumo de textos criam, por conseguinte, novos modos de difusão da informação, participando da formação de sentidos que sustentam posicionamentos sócio-políticos diversos. É o que se vê, por exemplo, por meio da rápida disseminação de notícias falsas que, muitas vezes, são distribuídas com base em fotomontagens e manipulação de imagens, sendo "legitimadas", não raro, pelo compartilhamento massivo e ligeiro entre os leitores. Compreendemos, assim, como Bauman (1992; 2009) e outros pensadores (GIDDENS, BECK, LASH, 1997), que vivemos dinâmicas sociais que se explicam pelo movimento, a dispersão, o fluxo.

Pesquisas no campo da cibercultura (LEVY, 1993, 1999, 2003), da comunicação social (ROBLEDO-DIOSES; ATARAMAROJAS, 2018; LOPES; CASTILLO, 2018) e dos estudos de linguagem (BUZATO et al, 2013) têm problematizado os modos de produção e circulação de informações no atual contexto de popularização do uso das tecnologias digitais. A proposta de que se incumbe este artigo, no entanto, tem um foco mais específico: o de problematizar as práticas interdiscursivas que constituem enunciados produzidos e disseminados no âmbito da internet, com especial atenção a seu conteúdo não-verbal, uma vez que, as imagens, integrantes dessas práticas intersemióticas, constituem um desafio para o campo da Análise do Discurso (AD) de base enunciativa, cujos desdobramentos de pesquisa têm construído uma longa tradição no estudo de textos em sua materialidade verbal. Diante de 
tal desafio, este artigo se propõe a apresentar um caminho analítico de um enunciado verbo-visual, observando-o pela perspectiva discursiva intersemiótica (MAINGUENEAU, 2008), e assumindo que se trata de um âmbito em que se dão disputas por estabilização de sentidos.

Situamo-nos no campo dos estudos do discurso, com base no entendimento de que, para além de uma simples representação de um dado estado de coisas no mundo, a linguagem detém um poder de intervenção no social (ROCHA, 2006; 2014), uma vez que possibilita a circulação de sentidos, constituindo e sendo constituída por uma dada conjuntura. Alinhamo-nos, então, a pesquisadores que vêm questionar o lugar do linguista na produção de um conhecimento responsivo a demandas sociais contemporâneas, sem, no entanto, abrir mão completamente de uma dimensão linguística, na qual a materialidade da língua, e de signos de outros tipos, desempenha um papel central na construção da realidade.

Em tempo, devemos considerar que o momento político atual, particularmente, nos motiva à participação nesse debate, por entendermos que a língua em uso, em todos os casos, é espaço para a manifestação de posicionamentos, algo que vemos com facilidade nas práticas linguageiras mais recentes, especialmente aquelas mobilizadas nos espaços das novas mídias digitais, que potencializam a produção e a circulação de discursos em concorrência. Portanto, compreendemos que, diante dos conflitos que abalam uma série de relações sociais, faz-se indispensável a intensificação da circulação de produções que mostrem o potencial da linguagem verbal e, especialmente, não-verbal, em termos de produção de sentidos e efeitos de verdade.

Partindo de tal compreensão, este artigo objetiva discutir o processo de captação e subversão (MAINGUENEAU, 1997) de um gênero do discurso intersemiótico no contexto da internet para produzir um posicionamento outro, marcado pelo embate entre diferentes formações discursivas. Para tal, partimos da compreensão dialógica de linguagem de Bakhtin, a partir da apreensão que lhe dá Maingueneau (2008) ao tratar do primado do interdiscurso.

No decorrer do texto, portanto, dedicamo-nos a articular contribuições da $\mathrm{AD}$ enunciativa, às propostas de Bakhtin quanto ao dialogismo e aos gêneros de discurso. Realizamos, ainda, breves análises, com base no gênero capa de revista e em sua captação 
como paródia - capa-paródia -, de maneira a exemplificar e dar visibilidade à produtividade dos conceitos mobilizados, propondo a reflexão sobre saberes produzidos em enunciados que circulam atualmente em nosso país sobre temas de natureza política. Todo esse caminho se desenvolve a partir de uma perspectiva de pesquisa comprometida com a construção de uma sociedade crítica e consciente diante das mais diversas práticas discursivas que constituem nosso cotidiano.

\section{Dialogismo, enunciação e interdiscurso: dialogando Bakhtin e Maingueneau na AD}

Com o propósito de discutir a teorização que dá sustentação a nossas análises, buscamos articular as propostas bakhtinianas de linguagem às da AD enunciativa de Dominique Maingueneau (1997, 2008). Entendemos que os ganhos de se enveredar por tal empresa são tanto de ordem epistemológica quanto política, uma vez que as reflexões do filósofo russo ampliam a compreensão da linguagem como prática social, permitindo-nos problematizar a produção de sentidos em disputa a partir de signos verbais e não verbais.

Para Bakhtin (1995, p. 113), "a palavra é território comum do locutor e do interlocutor". Ela comporta duas faces e é determinada por essa interação verbal: procede de alguém e se dirige para alguém. E essa relação não deve ser tomada como unidirecional, pois o autor afirma que a palavra é função da pessoa do interlocutor (tomado como sujeito concreto). Outra característica da teoria bakhtiniana de linguagem, é seu caráter fundamentalmente social, situado local e historicamente: "A situação social mais imediata e o meio social mais amplo determinam completamente e, por assim dizer, a partir de seu próprio interior, a estrutura da enunciação" (BAKHTIN, 1995, p. 113).

Na perspectiva bakhtiniana, enunciação e enunciado são duas faces de um mesmo processo - o de colocar a língua em uso por meio do discurso - que se materializa sempre em um gênero do discurso. Do entendimento que fazemos, a noção de gêneros do discurso, afastando-se de uma perspectiva essencialista ou que tome a língua como abstrata, possibilita articular as dimensões sócio- 
histórica e linguística no aqui e agora da enunciação, de modo a fotografar o instante, captar o fluxo, reconhecendo que um enunciado envolve enunciadores, coenunciadores, interação com enunciações anteriores (reais ou virtuais) e que tudo isso, como caracteriza Bakhtin (2000), está radicalmente imbricado ao modo como se articulam língua e social, não sendo o contexto algo acessório, externo, acrescentado posteriormente às enunciações. Maingueneau (2008), por sua parte, ratifica os postulados de Bakhtin, asseverando que:

A 'enunciabilidade' de um discurso, o fato de que tenha sido objeto de atos de enunciação por um conjunto de indivíduos não é uma propriedade que lhe é atribuída por acréscimo, mas algo de radical, que condiciona toda a sua estrutura. É preciso pensar ao mesmo tempo a discursividade como dito e como dizer, enunciado e enunciação. (2008, p. 19).

Diante do cotejo entre as propostas de Bakhtin e Maingueneau, chegamos à compreensão de que os gêneros de discurso, em todas as suas dimensões (composicional, temática e de estilo), têm suas estabilidades fundadas nas relações sociais de uma dada esfera de atividade humana. Essas dimensões, por se constituírem de modo relativamente estável, estão suscetíveis a especificidades das enunciações em que se manifestam, trazendo em sua origem as marcas de uma relação interdiscursiva. De modo mais concreto, por exemplo, o gênero capa de revista (cuja estabilidade nos traz à mente quase instantaneamente certo modo de organização do enunciado) possui marcas, em sua estrutura composicional, em seu estilo de linguagem e em sua temática, que dão pistas das relações interdiscursivas nas quais tal enunciado estabelece para si as especificidades de seu posicionamento dentro de uma dada formação discursiva.

Considerando as relações que estabelecemos entre os conceitos de gêneros discursivos, dialogismo e interdiscurso, cabe esclarecer que Maingueneau (2008), interessado na dimensão dialógica da enunciação de um discurso, teoriza o primado do interdiscurso. Para ele, o discurso é fundamentalmente heterogêneo, isto é, já nasce em relação com outros. É a partir da qualidade das relações entre discursos que se estabelecem suas fronteiras, sempre instáveis, resultado de um jogo de forças em movimento contínuo. 
Assim, interessa à $\mathrm{AD}$ a natureza interdiscursiva da enunciação, pois é por meio dela que se pode delimitar aquilo que constitui, ainda que provisoriamente, uma dada identidade ao discurso, caracterizando as fronteiras entre o que pertence ou não a uma dada formação discursiva.

Por formação discursiva, Maingueneau (2008) designa o sistema de restrições semânticas que opera sobre os modos verbais e não verbais de produção de sentidos de um discurso. Nessa visão, o que está em jogo não é uma gramática que gera enunciados, e sim uma semântica global que atua em diversos planos textuais intersemióticos (verbais e não verbais), nas condições de enunciação, bem como na dinâmica institucional pressuposta por todo discurso.

Visando tornar o conceito de interdiscurso menos vago e mais operacional, Maingueneau (2008, p. 33-34) o divide numa tríade: universo discursivo, espaço discursivo e campo discursivo. $\mathrm{O}$ universo discursivo engloba "o conjunto de formações discursivas de todos os tipos que interagem numa conjuntura dada", sendo uma noção que serve mais como horizonte para a construção dos campos discursivos, "um conjunto de formações discursivas que se encontram em concorrência, delimitam-se reciprocamente em uma região do universo discursivo", caracterizando "domínios suscetíveis de ser estudados" pelo analista. Já o espaço discursivo são "subconjuntos de formações discursivas que o analista, diante de seu propósito, julga relevante por em relação". No caso deste artigo, fazemos um recorte que parte da delimitação de um espaço discursivo em que concorrem a formação discursiva neoliberal ${ }^{1} \mathrm{e}$ uma formação que a ela se opõe, pautando-se na análise de uma capa da revista Exame e de uma paródia desse mesmo enunciado.

Segundo Maingueneau (2008), o espaço discursivo teria um duplo estatuto: servir como modelo dissimétrico que permite a descrição da constituição de um discurso e, simultaneamente, como modelo simétrico de interação conflituosa entre dois discursos em relação de alteridade um para com o outro. Neste artigo, o que nos interessa é o segundo aspecto, que nos permite descrever a constituição de um discurso segundo, materializado intersemioticamente na paródia de uma capa de revista que nos serve

${ }^{1}$ Para uma discussão sobre neoliberalismo ver Ianni (1998). 
de material de análise. Assim, considerando o discurso da paródia como um discurso que se constituiu por força de um movimento dialógico em relação ao discurso primeiro - a capa -, busca-se compreender a rede semântica que rege esse discurso e como define sua identidade no interior de uma dada formação discursiva.

Partimos da premissa de que o sistema de restrições que rege a produção de enunciados verbais de uma dada formação discursiva também atua como filtro daquilo que pode / deve ser enunciado por meio de signos não verbais assumidos por sujeitos e instituições que aderem a esta mesma formação discursiva. Conforme Maingueneau (2008), "o pertencimento a uma mesma prática discursiva de objetos derivados de domínios semióticos diferentes exprime-se em termos de conformidade a um mesmo sistema de restrições semânticas" (MAINGUENEAU, 2008, p. 138).

Nessa direção, o linguista eleva o conceito de prática discursiva ao patamar de unidade de análise, entendendo sua pertinência e seu potencial para "integrar domínios semióticos variados: enunciados, quadros, obras musicais..." (Maingueneau, 2008, p. 139). A partir disso, defende que seria possível falar em práticas intersemióticas, uma vez que esses domínios semióticos diversos, longe de serem estruturalmente isomórficos, sofrem restrições semânticas de seu sistema de formação discursiva. Em outras palavras, bem como afirma o analista do discurso, defendemos a compreensão de que, no interior de uma mesma formação discursiva, os produtores de textos não verbais (fotógrafos, pintores, escultores, compositores e, mais recentemente, sujeitos que atuam com a criação, edição e manipulação de imagens no âmbito digital), possuem a mesma competência discursiva que os enunciadores de textos verbais, isto é, uma vez que "participam da mesma prática discursiva, dispõem da mesma rede de regras [...] para tratar os materiais significantes" (MAINGUENEAU, 2008, p. 140).

Na relação entre práticas discursivas que disputam o mesmo espaço para dizer algo sobre um determinado tema, cada enunciador no interior de sua formação discursiva, demonstra sua competência discursiva ao produzir enunciados que seguem as restrições semânticas que se lhe são impostas. Isto se dá tanto na escolha de um gênero do discurso específico, quanto no uso de diferentes linguagens verbais e não verbais. No entanto, para se constituir como tal, o discurso precisa recusar aquilo que lhe é estranho. Esse 
processo, tendo em vista o dialogismo constitutivo e o primado do interdiscurso não é completamente possível, deixando marcas desse outro no mesmo. Essa heterogeneidade discursiva pode, portanto, materializar-se de distintas formas, como discursos relatados, negações polêmicas, implícitos e também aquilo que a retórica tradicional chamou de paródia.

Maingueneau (1997, p. 102) engloba as paródias em um fenômeno de heterogeneidade mais amplo, diretamente relacionado aos gêneros de discurso, que designa imitação. Para ele, "a imitação de um gênero pode assumir dois valores opostos: a captação e a subversão". A captação se dá quando "a imitação incide sobre a estrutura explorada" para legitimar seu próprio discurso, já a subversão produz desqualificação deste mesmo gênero no movimento de sua imitação. O linguista ainda explica que "a subversão mantém uma distância entre duas fontes de enunciação que ela hierarquiza", contudo, aproximando-se da ironia, onde há a sobreposição de duas vozes simultâneas não marcadas, a subversão não se apresenta como tal, expondo como responsável uma única fonte enunciativa. Na busca por melhor especificar o fenômeno da imitação, o autor distingue quatro casos: a) captação de um gênero; b) captação de um texto singular e seu gênero; c) subversão de um gênero; d) subversão de um texto singular e seu gênero (MAINGUENEAU, 1997, p. 102).

A partir das análises que ora apresentamos, argumentamos em favor não de uma oposição entre captação e subversão, como sustenta Maingueneau (1997), mas pelo entendimento que, no contexto da internet, com intensa produção intersemiótica de textos verbo-visuais que parodiam outros, esses dois valores formam parte de um mesmo processo enunciativo. Um texto de um gênero específico pode ser captado, tendo sua estrutura mantida ou modificada por meio de procedimentos de edição digital, como colagens, distorções e inclusões de enunciados textuais, e subvertido, de modo a operar uma crítica, uma ridicularização e/ou produzir humor sobre a fonte enunciativa do outro texto. Visando demonstrar tal processo em uma prática discursiva intersemiótica, passamos às análises dos enunciados. 


\section{3 "O que você e ele não têm em comum": análise discursiva de uma prática intersemiótica}

No intuito de ultrapassarmos as ponderações teóricas, recorremos a enunciados postos em circulação no início de 2017. O primeiro deles é a capa da revista Exame, edição 1129, ano 51, número 1 , de 18 de janeiro ${ }^{2}$ (que começou a circular no dia 12 do mesmo mês), na qual se apresenta, no âmbito do não verbal, a imagem do músico britânico Mick Jagger - integrante da banda Rolling Stones, mundialmente conhecida - associada a uma parte verbal que anuncia um olhar que podemos afirmar ser positivo sobre a reforma da previdência proposta pelo, então, governo de Michel Temer. Na fotografia que ocupa a maior parte da área da capa, alinhada do centro para o lado direito, o músico britânico aparece sentado, olhando para o leitor com um semblante sério, com os braços cruzados e apoiados em uma mesa de madeira (a imagem do cantor é a mesma utilizada no meme, com o rosto modificado, como se pode ver na figura 1). A imagem localiza-se em um espaço intermediário entre duas camadas de texto. Ao fundo, por trás da imagem, apresenta-se o nome da revista, os dados da publicação e algumas chamadas. E na primeira camada, sobre a fotografia, alinhado à esquerda, temos o seguinte texto:
A NOVA APOSENTADORIA
O que você e ele têm em comum?
Talvez não seja a fortuna, nem o rebolado, nem os oito filhos.
Mas, assim como Mick Jagger, você terá de trabalhar velhice adentro.
A boa notícia: preparando-se para isso, vai ser ótimo.

O segundo enunciado ao qual fazemos referência, e cuja leitura articulamos aos pressupostos teóricos que aqui sustentamos, é uma paródia - a que convencionamos chamar capa-paródia - que

\footnotetext{
${ }^{2}$ Disponível em https://exame.abril.com.br/edicoes/1129/. Acesso em 25 de novembro de 2019.
} 
passou a circular na internet também no dia 12 de janeiro de 2017, veiculada pela página de Facebook intitulada Soldadinho de Chumbo, em resposta à publicação da Exame e em oposição ao seu ponto de vista.

Figura 1: Paródia da capa da Revista Exame feita por Soldadinho de Chumbo.

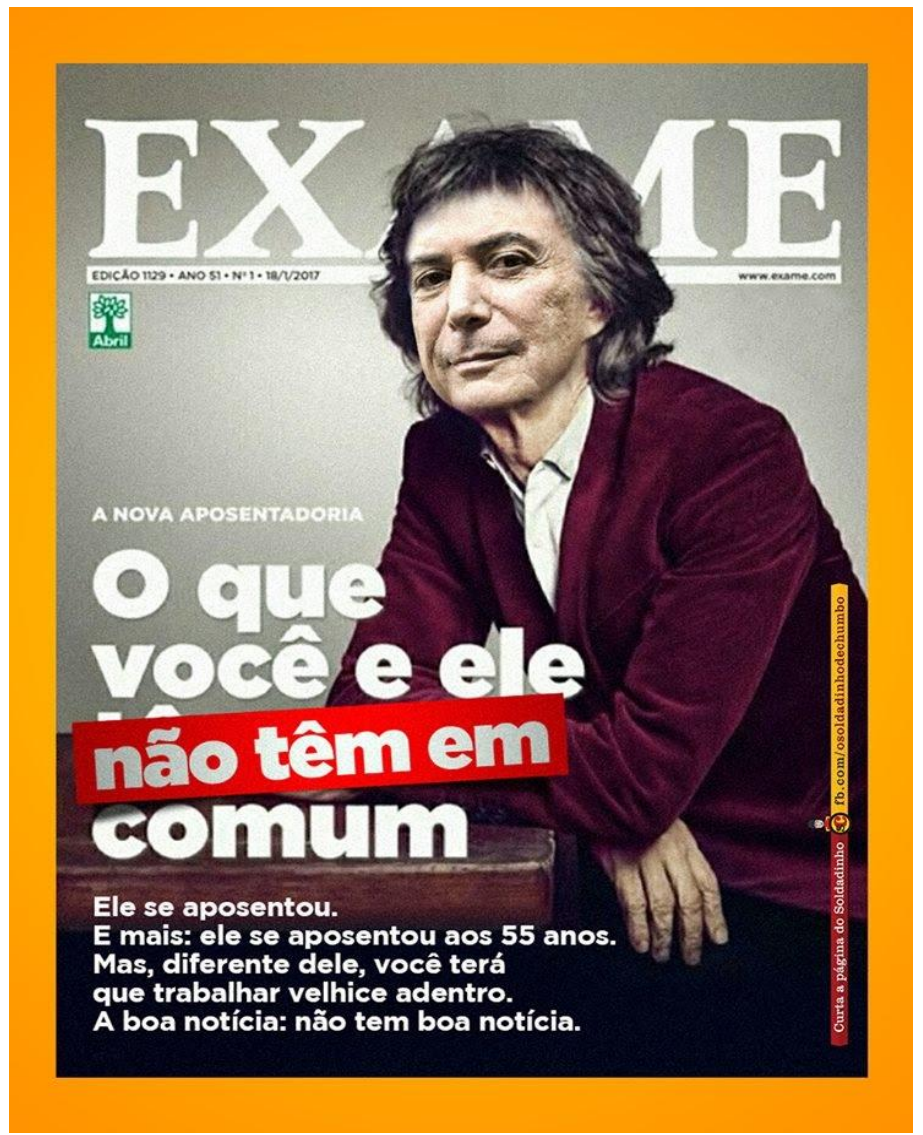

A capa de revista apresentada é um gênero de discurso, como propõe Bakhtin (2000); tipos de enunciado que se tornam 
relativamente estáveis por sua repetição, incluída aí a própria paródia que, conforme discutiremos, funda-se ao captar e subverter este mesmo gênero. Nesse sentido, entendemos que o gênero constitui o ato de colocar em ação recursos lexicais, construções frasais, entonações para dar conta de demandas específicas das esferas de atividade humana nas quais tais gêneros são criados.

Maingueneau (2008, p. 139) afirma que, o gênero "impõe restrições que se relacionam com o contexto histórico e com a função social dessa prática". Desse modo, implica coerções que devem ser estabelecidas a fim de que um enunciado possa ser legitimado no seu interior. Tais coerções seriam o status de enunciadores e coenunciadores; as circunstâncias temporais e os locais da enunciação; o suporte e os modos de difusão; os temas que podem ser introduzidos; e a extensão e modo de organização.

Tanto o enunciado-capa quanto a capa-paródia nos ajudam a compreender a perspectiva dialógica da linguagem e o primado do interdiscurso. Em ambos os casos, os sentidos surgem em uma situação de enunciação que envolve um momento, local e coenunciadores legítimos, assim, o entendimento da capa da revista não passa por uma busca por "desvendar" o que está no íntimo do grupo ou indivíduo que a criou, mas por construir sentidos a partir de questões como: o papel social da revista responsável pela capa e os posicionamentos que costuma assumir, o momento político vivido, o papel social de Mick Jagger trazido como referência, e também pela apreensão das finalidades do gênero capa - seja o de chamar a atenção do público para a revista ou mesmo o de reforçar o suposto caráter informativo e o efeito de sentido de neutralidade em relação aos conteúdos que faz circular.

Recuperando o que assevera Bakhtin (2000) sobre o reconhecimento de características particulares que distinguem um gênero de outro e permitem ao interlocutor estabelecer as bases do seu entendimento, um texto inscrito em determinado gênero fornece pistas por meio das quais esse interlocutor pode se situar dentro do contexto da comunicação, prevendo suas características e finalidades. A capa da revista, como dissemos, tem como finalidade divulgar o conteúdo considerado principal pela mesma, usando uma combinação de linguagens verbal e não-verbal, de modo a provocar no leitor o interesse por sua leitura. Cabe especificar que a revista em questão, Exame, é uma publicação quinzenal, pertencente ao Grupo 
Abril, cujo foco - segundo a própria - se volta a temas como "negócios, economia, tecnologia e carreira"3, direcionando-se explicitamente a profissionais do ramo dos negócios, como empresários, empreendedores e demais interessados. Adicionalmente, suas práticas discursivas se orientam, em geral, por pautas do mercado econômico, e se constituem em uma formação discursiva que se norteia por um posicionamento alinhado a um discurso neoliberal.

Sua capa, portanto, se formula com base em uma série de diálogos estabelecidos com outros enunciados, como com a reforma registrada na Proposta de Emenda à Constituição (PEC) n. 287 de 2016 - marcado pela designação "a nova aposentadoria" -, com notícias e informações que circulam na mídia sobre a vida de Mick Jagger - sinalizado pela menção a seu patrimônio, à quantidade de filhos que tem -, com certas concepções de trabalho, ao referir-se a "uma nova era no trabalho". Tudo isso ratifica a proposta de Bakhtin para quem, as enunciações apenas ganham existência no contato dialógico com outras enunciações, caracterizando o discurso como constitutivamente heterogêneo, marcado pela alteridade das palavras dos outros.

A capa-paródia, por sua vez, confirma que o leitor, que em algumas perspectivas é tido como um sujeito passivo, atua discursivamente a partir dos sentidos que atribui ao que lê, sempre ancorado local e historicamente, ressignificando, contestando ou reiterando, e participando essencialmente do fluxo discursivo. A capa-paródia ao captar, subverter e enunciar a partir de outra formação discursiva, também contribui com a desnaturalização dos enunciados da capa da Exame, evidenciando que não há neutralidade ou imparcialidade possível no discurso jornalístico ou qualquer outro.

Nossa argumentação reforça a afirmação de Bakhtin (2000) de que todo interlocutor é ativo no processo de compreensão dos enunciados do outro e que a aparente passividade do ouvinte é apenas o "elemento abstrato de um fato real que é o todo constituído pela compreensão responsiva ativa" (BAKHTIN, 2000, p. 291). Conforme o autor, a compreensão responsiva ativa "nada mais é

${ }^{3}$ Disponível em $<$ https://exame.abril.com.br/>. Acesso em: 25 de novembro de 2019. 
senão a fase inicial e preparatória para uma resposta" (BAKHTIN, 2000, p. 291), que pode se apresentar de diferentes formas e em diferentes tempos e constitui uma atitude de concordância ou discordância, de adesão, de objeção, podendo se dar na forma da execução de atividade(s) não linguísticas etc.

Bakhtin compreende que todo discurso é duplamente dialógico, ou seja, o diálogo se estabelece em dois planos simultâneos e interdependentes. Em um deles, o diálogo constitui o produto da interação entre um locutor e seu(s) interlocutor(es). No outro, figura como um elo na cadeia infinita de discursos, mantendo sempre relações com os já produzidos anteriormente e provocando respostas de futuros. O dizer é sempre uma reação-resposta a outros enunciados (BAKHTIN, 2000). Nesse mesmo sentido, podemos remeter aos construtos de interdiscurso e prática discursiva de Maingueneau (2008), segundo os quais um discurso se institui e delimita seus posicionamentos a partir da relação de alteridade com os demais discursos aos que se opõe.

Desse modo, a capa da Exame sinaliza essa "reação-resposta" a outros enunciados e o atravessamento por outros discursos. $\mathrm{O}$ trecho "a boa notícia", por exemplo, tanto retoma os discursos que rejeitam a reforma - afinal, se há a necessidade de ressaltar a "boa" notícia é porque o lado ruim estaria mais evidenciado -, como promove outros discursos que defendem a necessidade de uma "nova era no trabalho", a qual, na ótica de certos posicionamentos, só seria possível por meio da proposta de reforma previdenciária.

Já nos termos do plano de diálogo entre locutor e interlocutores, podemos retomar não apenas a capa-paródia, que recusa o ponto de vista da revista, mas também uma série de memes publicados em redes sociais como o Twitter que, além de tudo, reforçam a inextricável relação da língua com o social - mostrando que existem diferentes maneiras de se conceber o "trabalho". Para exemplificar, relacionamos alguns dos que mostram diferentes fatores que caracterizam, em parte, a questão do trabalho no Brasil: "Mick Jagger esperando perícia do INSS pra comprovar que não aguenta mais cantar durante 2h"; "Mick Jagger perguntando "Caiu o VR?" antes do almoço"; "Mick Jagger usando o banco de horas pra 
vir até o Brasil visitar o filho Lucas"; "Mick Jagger felizão porque saiu o quinto lote de restituição do IR" .

Tendo em vista o primado do interdiscurso e os pressupostos de que a linguagem é sempre dialógica, e dirigida a uma audiência, faz-se necessário pensar as formas de organização social que dão inteligibilidade aos modos de ser e de agir no mundo. Partindo do exemplo que nos propomos a debater, vemos como a internet, nos tempos atuais, possibilita novos caminhos de ação no mundo, tornando também mais palpável a apreensão do dialogismo e da interdiscursividade na linguagem e observando que

Os enunciados não são indiferentes uns aos outros, nem são auto-suficientes; conhecem-se uns aos outros, refletem-se mutuamente. São precisamente esses reflexos recíprocos que lhes determinam o caráter. $\mathrm{O}$ enunciado está repleto dos ecos e lembranças de outros enunciados, aos quais está vinculado no interior de uma dada esfera comum da comunicação verbal (BAKHTIN, 2000, p. 316)

Dessa maneira, uma capa de revista que, em outros tempos, assumia um status privilegiado de gênero informativo, supostamente neutro, passa a poder ser questionada, ressignificada, subvertida e, consequentemente, deslegitimada, especialmente devido à popularização de ferramentas digitais que facilitam a edição de imagens e também do advento da internet que favorece a rápida circulação de conteúdos. Assim, vemos que aquilo que se diz é intrínseco a seus modos de produção, uma vez que

cada época e cada grupo social têm seu repertório de formas de discurso na comunicação sócio-ideológica. A cada grupo de formas pertencentes ao mesmo gênero, isto é, a cada forma de discurso social, corresponde um grupo de temas. Entre as formas de comunicação (por exemplo, relações entre colaboradores num contexto puramente técnico), a forma de enunciação ("respostas curtas" na "linguagem de negócios") e enfim o tema, existe uma unidade orgânica que nada poderia destruir (BAKHTIN, 1995, p. 42)

${ }^{4}$ Disponível em: $<$ http://portal.comunique-se.com.br/revista-exame-comparabrasileiros-a-mick-jagger-trabalhar-velhice-adentro/>. Acesso em: 29 ago. 2017. 
A capa da revista, parte do repertório contemporâneo de formas de discurso, além de divulgar seu principal conteúdo, faz circular, tanto nos espaços físicos onde se pode encontrar a revista, quanto nos espaços virtuais, determinados posicionamentos de uma comunicação sócio-ideológica, que no caso em análise, remete a uma certa concepção positiva sobre a reforma da previdência proposta pelo governo Temer, construída simultaneamente pela dinâmica de interlocução, pelo contexto sócio-histórico e pelos recursos linguísticos e imagéticos em uso. $\mathrm{O}$ mesmo ocorre com a capaparódia que, integrando um repertório contemporâneo de produções no âmbito digital, mostra-se como uma enunciação que desestabiliza a esfera jornalística, assume o papel de crítica e de denúncia dos posicionamentos manifestados pelo enunciado-capa, por meio de um registro humorado e satírico marcados não apenas nos enunciados verbais, mas igualmente nos não verbais.

A foto de Mick Jagger sentado diante de uma mesa - e não nos palcos, como de costume -, o projeta como um homem de sucesso, um trabalhador como os demais, que por sua idade já poderia estar aposentado, mas que segue trabalhando, e bem, em conjunto com enunciado "O que você e ele tem em comum", marcado pelo uso de pronomes pessoais dêiticos, dialoga diretamente com o leitor, forçando uma relação de identificação com o rockeiro, necessária em um momento em que o governo de Temer tinha como objetivo a produção de políticas que propunham a redução dos direitos dos trabalhadores, como o aumento da idade de aposentadoria, o que, da perspectiva de Maingueneau (2008), se estabelece pelas restrições semânticas de uma formação discursiva neoliberal.

Do mesmo modo, a capa-paródia constitui-se ao captar e subverter o gênero capa de revista para, não somente dar existência à formulação de um enunciado-resposta ao discurso da revista, como para desqualificá-lo em seu posicionamento político-ideológico. Ao substituir o rosto do artista pelo de Michel Temer, por meio de recurso de edição digital, e acrescentar uma negação no enunciado anterior, agora "O que você e ele não têm em comum", o enunciador intervém no mundo social, fornecendo uma contrapalavra, uma réplica, demonstrando sua compreensão do discurso do outro, e 
outrossim, é possível afirmar que tal enunciado alinha-se a uma formação discursiva que se opõe ao discurso neoliberal.

Socialmente, a reforma da previdência tem seu processo de significação caracterizado por diferentes formas de entendê-la, o que caracteriza sentidos em disputa por duas formações discursivas distintas em práticas discursivas que dialogam. o que caracteriza sentidos em disputa por duas formações discursivas distintas em práticas discursivas que dialogam. Os enunciados que nos propusemos a analisar nos permitem observar, no campo dos estudos do discurso - com base nos conceitos de dialogismo, interdiscurso, gêneros dos discursos, captação e subversão - a convivência conflituosa dessas duas posições discursivas, que longe de apenas representarem um mundo dado, constroem suas próprias versões da realidade (ROCHA, 2006, 2014).

Depreendemos das análises realizadas, afinal, que os enunciados, lidos numa perspectiva (inter)discursiva dialógica, nos permitem perceber toda uma caracterização positiva da reforma previdenciária na revista Exame, considerando um recorte que evidencia como referência - ao comparar trabalhadores brasileiros com Mick Jagger - uma realidade de trabalho privilegiada, uma situação financeira muito próspera e uma relação com o trabalho que não se sustenta na necessidade de garantia de condições dignas mínimas para se viver. Por conseguinte, a leitura na perspectiva dos gêneros do discurso nos permite compreender que a seleção do cantor como referência se vincula ao posicionamento ideológico deste meio de comunicação, a sua formação discursiva, conforme explicitado, e também à própria finalidade do gênero: promover a leitura da revista, da matéria e, consequentemente, em certa medida, difundir o ponto de vista apresentado.

Por outro lado, ambos os enunciados (capa da exame e capaparódia) nos colocam diante da produção e circulação de sentidos que considera a competência discursiva e o caráter responsivo ativo dos interlocutores. Nos dois casos, percebemos ressignificações, ou melhor, uma busca por (des)qualificar e caracterizar, sob um olhar específico, a referida proposta do governo federal. A capa-paródia, especificamente, assim como os memes explicitados como exemplo, apresenta, ao captar e subverter a capa da revista de forma satírica e bem humorada - algo típico da esfera midiática na qual se inserem os novos gêneros circulantes na internet -, um outro ângulo no que 
se refere às características do trabalho no Brasil. Tendo em vista a finalidade da crítica ao enunciado-capa da Exame, a capa-paródia, como é típico em um processo de captação, mantém a estrutura composicional e o estilo do gênero capa de revista, mas, ao subvertê-la, descaracteriza o tom de verdade - assumido pelos meios de comunicação da esfera jornalística - e desqualifica o enunciador de Exame, por meio da manipulação da imagem, antes, um rockstar, e agora um político e presidente do país; e também por meio da tarja vermelha que chama a atenção para o texto modificado - "não têm em comum".

Enfim, o percurso teórico-analítico que acabamos de traçar nos mostra o modo pelo qual práticas discursivas intersemióticas são um espaço para a manifestação de disputas do campo social. Os recursos linguísticos como os dêiticos pessoais, as formas de designação, a negação, a articulação com diferentes textos não verbais, tudo isso vinculado a diferentes esferas de atividade humana com suas finalidades específicas, assinala a complexidade do uso da língua(gem) e a necessidade de compreendê-la por um viés crítico, tal como buscamos ilustrar.

\section{Considerações finais}

Ao longo deste artigo, procuramos analisar o processo de captação e subversão de uma capa de revista por meio de uma paródia, feita com uso de ferramentas digitais para circular na internet, sobre a proposta da reforma da previdência. Para tal, discutimos os conceitos de gêneros de discurso e dialogismo de Bakhtin em articulação à perspectiva da $\mathrm{AD}$ enunciativa de Maingueneau, por meio dos construtos de interdiscurso, prática intersemiótica, subversão e captação, como um caminho que permite pensar a língua(gem) em suas dimensões sócio-histórica, linguística e também em dada situação de enunciação específica. Nosso intuito, em termos gerais foi o de contribuir para o debate sobre os desafios de se analisar textos verbo-visuais que circulam no contexto da internet na contemporaneidade, reforçando a importância da análise de práticas discursivas midiáticas tanto para criar inteligibilidade sobre a vida social e política do país, quanto para intervir nessa construção de sentidos. 
Frente ao desafio de propor análises e reflexões teóricas sobre práticas intersemióticas a partir de uma perspectiva que considere as tensões e as disputas por sentidos de sociedade em jogo, retomamos nosso argumento inicial acerca da importância e relevância de tratar a linguagem como modo de construção social pela qual podemos desnaturalizar verdades estabelecidas e produzir formas de viver mais éticas e coletivas.

Como vimos, os sentidos são construídos a partir de um conjunto de fatores, elementos verbais e não verbais, numa dada situação de enunciação que mobiliza diversos pontos de vista, papéis dos atores sociais envolvidos, finalidade dos ditos, suportes e meios de publicação / circulação - que, ademais, sinalizam diferentes possibilidades de intervenção no mundo pela língua(gem) - verbal e não verbal. Por conseguinte, recuperamos as palavras de Bakhtin, de modo a corroborar que, para lidar com o fluxo de enunciados, depreendendo-os como possibilidades de significação e criação de efeitos de verdade, é preciso considerar que "A compreensão é uma forma de diálogo; ela está para a enunciação assim como uma réplica está para a outra no diálogo. Compreender é opor a palavra do locutor uma contrapalavra" (BAKHTIN, 1995, p. 135).

Por fim, destacamos que, sendo o discurso a nossa porta de entrada para reflexões sobre a intrínseca relação da linguagem com o social, acreditamos na possibilidade de se recuperar sentidos que se inscrevem na materialidade discursiva e permitem o acesso a uma melhor compreensão da organização dos diversos posicionamentos possíveis e de sua relação com uma conjuntura maior, da qual participam. Para nós, esse é um caminho produtivo que, para além da pesquisa acadêmica, fomenta a educação linguística na direção da formação de leitores autônomos, cientes do poder de intervenção da linguagem, por permitir um engajamento com as demandas sociais de nosso tempo, cujos sentidos não se produzem unilateralmente.

\section{REFERÊNCIAS}

BAKHTIN, M. Estética da criação verbal. São Paulo: Martins Fontes, 2000.

BAKHTIN, M. / VOLOCHINOV, V. N. Marxismo e filosofia da linguagem. São Paulo: Huicitec, 1995. 
BAUMAN, Z. Intimations of postmodernity. Londres: Routledge, 1992.

BAUMAN, Z. Modernidad líquida. Buenos Aires: Fondo de Cultura Económica, 2009.

BUZATO, M El Khouri et al. Remix, mashup, paródia e companhia: por uma taxonomia multidimensional da transtextualidade na cultura digital. Revista Brasileira de Linguística Aplicada, Belo Horizonte, v. 13, n. 4, p. 1191-1221, dez. 2013. Disponível em: $<$ http://dx.doi.org/10.1590/S1984-63982013000400011>. Acesso em: 30 nov. 2019.

GIDDENS, A.; BECK, U.; LASH, S. Modernização reflexiva: política, tradição e estética na ordem social moderna. São Paulo: Editora da UNESP, 1997.

LÉVY, P. As tecnologias da inteligência. São Paulo: Editora 34, 1993.

LÉVY, P. Cibercultura. São Paulo: Editora 34, 1999.

LÉVY, P. A inteligência coletiva. Por uma antropologia do espaço. São Paulo: Loyola, 2003.

LOPES, M. I. V. de; CASTILHO, F. Recepção transmídia: perspectivas teórico-metodológicas e audiências de ficção televisiva online. Galáxia, São Paulo, n.39, p.39-52, dez. 2018. Disponível em: $<$ http://dx.doi.org/10.1590/1982-255435151>. Acesso em: 30 nov. 2019.

MAINGUENEAU, D. Análise de textos de comunicação. 6. ed. ampl. São Paulo: Cortez, 2013.

MAINGUENEAU, D. Gênese dos discursos. São Paulo: Parábola Editorial, 2008.

MAINGUENEAU, D. Novas tendências em Análise do Discurso. 3. ed. Campinas, SP: Pontes, 1997.

REVISTA EXAME. São Paulo, edição 1129, ano 51, n.1, 18 jan. 2017. Editora Abril, 2017. Disponível em: $<$ http://exame.abril.com.br/edicoes/1129/>. Acesso em: 29 ago. 2017. 
ROBLEDO-DIOSES, K.; ATARAMA-ROJAS, T. Periodismo transmedia y consumo mediático de la generación millennials. Anagramas - rumbos y sentidos de la comunicación. Medellín, v. 17, n.33, p.105-127, dez. 2018. Disponível em: $<$ http://dx.doi.org/10.22395/angr.v17n33a5>. Acesso em: 30 nov. 2019.

ROCHA, D. Representar e intervir: linguagem, prática discursiva e performatividade. Linguagem em (Dis)curso (Online), v. 14, p. 619-632, 2014. Disponível em: $<$ http://www.scielo.br/pdf/ld/v14n3/1518-7632-ld-14-03-00619.pdf> Acesso em: 15 ago. 2017.

ROCHA, D. Representação e intervenção: produção de subjetividade na linguagem. Gragoatá. Niterói: Ed. UFF, v. 21, p. 355-372, 2006. Disponível em: $<$ http://www.gragoata.uff.br/index.php/gragoata/article/view/317/31 8> Acesso em: 15 ago. 2017.

SOLDADINHO DE CHUMBO. Disponível em: $<$ https://scontent.fsdu51.fna.fbcdn.net/v/t1.09/15894844_1280826178644700_1004774346 0781515_n.jpg?oh=0fe5a2059a41fdf6b33244c5d4962710\&oe=5A2 5A202>. Acesso em: 29 ago. 2017. 